\title{
DISTRIBUIÇÃO DE HORTALIÇAS E RAÍZES EM ITABAIANA/SE
}

\author{
Distribution Center for Vegetables and Roots in Itabaina/Sergipe \\ Diana Mendonça de Carvalho* \\ José Eloízio da Costa**
}

\begin{abstract}
Resumo
O espaço tem se diversificado como base operacional a serviço do capital, onde o trabalho humano se materializa na produção de mercadorias. Neste sentido, a relação campo-cidade é tratada como complementar e suas articulações às redes de comercialização agrícola adentram nas instâncias da circulação dessas mercadorias. Por conseguinte, o presente artigo buscará analisar a abrangência e os alcances das redes de distribuição das principais hortaliças e raízes produzidas e comercializadas em Itabaiana/SE, a partir da definição dos espaços de comercialização e de distribuição. Para tanto foi realizada pesquisa bibliográfica e trabalho de campo junto aos comerciantes e consumidores desses segmentos. Tais aspectos contribuíram para a organização dos fluxos de hortaliças e raízes no sentido das importações e exportações. Logo, visualizou-se que os fluxos ocasionados por esses produtos estimularam o enlace da relação campo-cidade nacional, regional e local, assim como estimularam a transformação do município de Itabaiana em principal centro de distribuição de hortaliças e raízes do Estado de Sergipe.
\end{abstract}

Palavras-chave: Fluxos, Redes, circulação, distribuição, comercialização.

Abstract
The area has diversified operating base in the capital's service, where human labor is embodied in the pro-
duction of goods. In this sense, the rural-urban relationship is treated as complementary and their links to
networks of trade in agricultural gets in instances of movement of these goods. Therefore, this article will
try to analyze the breadth and scope of distribution networks in the main roots and vegetables produced and
marketed in Itabaiana / SE, from the definition of the areas in marketing and distribution. Were performed
literature search and field work at merchants and consumers in these segments. These aspects contributed
to the organization of streams and root vegetables in the direction of imports and exports. Thus, that flows
caused by these products are stimulating the binding ratio, rural-urban national, regional and local levels, as
well as the transformation of Itabaiana town in main distribution center for vegetables and roots in Sergipe.

Key words: Flows, networks, circulation, distribution and marketing

\section{Resumen}

El área se ha diversificado base de operaciones al servicio de la capital, donde se plasma el trabajo humano en la producción de mercancías. En este sentido, la relación rural-urbana se considera como complementaria y su relación con las redes del comercio en los casos adentram agrícola de movimiento de estas mercancías. Por lo tanto, este artículo intenta analizar la amplitud y el alcance de las redes de distribución de las raíces principales y hortalizas producidas y comercializadas en Itabaiana / SE, de la definición de las áreas de marketing y distribución. Se le realizó la búsqueda en la literatura de ambos y el trabajo de campo en los comerciantes y los consumidores de estos segmentos. Estos aspectos contribuyeron a la organización de los arroyos y vegetales de raíz en la dirección de las importaciones y las exportaciones. Por lo tanto, visto que los flujos causados por estos productos estimulado la relación vinculante zonas rurales y urbanas a nivel nacional, regional y local, así como estimular la transformación de la Municipalidad de Itabaiana en el centro principal de distribución para las hortalizas y las raíces del estado de Sergipe.

Palabras clave: Flujos, redes, circulación, distribución y comercialización.

(*) Msc. pelo Núcleo de Pós Graduação em Geografia da Universidade Federal de Sergipe - Cidade Universitária Prof. José Aloísio de Campos, S/N. CEP: 49.100-000, São Cristovão (SE) - Brasil, Tel.: (+ 55 79) 32126742 - dianamendoncadecarvalho@ yahoo.com.br

(**) Prof. Dr. da Pós Graduação em Geografia da Universidade Federal de Sergipe - Cidade Universitária Prof. José Aloísio de Campos, S/N. CEP: 49.100-000, São Cristovão (SE) - Brasil, Tel.: (+55 79) 32126742 - eloizio@ufs.br 


\section{INTRODUÇÃO}

As relações entre a sociedade e seus espaços locais passam a depender cada vez mais de forças externas que dominam o espaço, orientam a produção e a circulação das mercadorias. Por conseqüência, o espaço tem se diversificado como base operacional a serviço do capital, onde o trabalho humano se materializa na produção de mercadorias.

Neste sentido, o campo se especializou na produção de gêneros que satisfizesse as necessidades próprias e da cidade, mesmo que de forma desigual. Enquanto a cidade passou a produzir para fornecer bens e serviços de necessidade para o campo. Isto acontece porque essa relação não tem suas particularidades anuladas, ao contrário, são fontes de integração e de cooperação. Tal relação não tem gerado nítida separação entre os trabalhadores rurais e urbanos, levando-se em conta que a tradição cultural do meio rural assume posição de destaque no contexto global, ao produzir e agregar novas tecnologias de processamento.

Essa articulação também ocorre a partir da integração entre agricultores e empresas industriais ou comerciais, refletindo relações sociais que se medeiam na relação agricultura-mercado. A integração produtor-mercado advém dos diferentes estágios do processo produtivo que exige do mercado, produtos cada vez mais homogêneos e com características definidas. Esse processo não só se coloca como um estágio no modo de acumulação capitalista, como também se torna referência da "globalização" no meio rural, a partir da definição de redes e fluxos de comercialização.

As redes remetem ao fluxo de mercadorias, pessoas, informações e idéias. Esses fatores proporcionam a circulação, uma vez que, a economia de mercado se compõe pela produção, circulação, distribuição e consumo.

A circulação resulta no aumento de fluxos que conduzem à reprodução ampliada do capital. Sendo assim, a circulação se reflete na ampliação dos fluxos. O aumento no volume desses fluxos e, conseqüentemente, de sua velocidade tem sido decorrente dos sistemas de comunicação e transporte que elevam o grau de fluidez da sociedade, isto é, criam meios ágeis na transmissão de informações e mercadorias destinadas a favorecer a fluidez do capital. Isso se reflete na articulação das redes espaciais e regionais, pois se faz conhecer os espaços e os pontos entrecruzados por linhas que tratam da articulação de fluxos materiais e imateriais. Sendo assim, esses fluxos podem se remeter aos fluxos de importação e exportação.

A importação de produtos agrícolas tende a ocorrer em função da demanda do consumo interno e devido aos fatores naturais e comerciais. Os produtos importados contabilizam maior quantidade e agregam valores superiores em relação aos produtos internos exportados e, normalmente, são comercializados em locais com infra-estrutura e sofisticação, a exemplo de supermercados e lojas ou vendedores especializados. Além disso, a importação de produtos agrícolas depende da sazonalidade e da representação dos principais componentes comerciais, como por exemplo, o preço das mercadorias, a reserva de mercado e a ausência de credibilidade para o intermediário. Quanto à exportação, há um favorecimento pela maior quantidade de um mesmo produto disponível no mercado que através de canais multiformes e multidimensionais intensificam os diversos meios de comercialização.

Logo, a finalidade desse trabalho é analisar a abrangência e os alcances das redes de distribuição das principais hortaliças e raízes produzidas e comercializadas em Itabaiana/SE, a partir da definição dos espaços de comercialização e de distribuição. A pergunta de pesquisa que fundamentou o referido trabalho foi: A distribuição de hortaliças de/por Itabaiana tem apresentado alcances que sustentem o mercado de comercialização do município? Para tanto, partiu-se da avaliação do conteúdo técnico e econômico das redes de comercialização que articulam a relação campo-cidade de e em Itabaiana/SE.

O espaço de estudo, o município de Itabaiana, localiza-se na faixa centro-ocidental do estado de Sergipe. A escolha desse espaço se justifica, na tentativa de contribuir para o entendimento das relações comerciais estabelecidas entre o produtor e o consumidor, na aquisição dos produtos agrí- 
colas, no município de Itabaiana. Fato decorrente desse espaço se destacar como maior centro de comercialização e distribuição de hortifrutigranjeiros no estado de Sergipe.

A fim de desenvolver esse trabalho se tomou como etapas: 1- Levantamento bibliográfico a respeito de comercialização agrícola, cujos pensadores principais foram: FERRÃO (2005), SANTANA (2005) e VILELA (1999); 2- Fora utilizado como categorias de análise geográficas: Espaço e Redes; 3- Realizou-se levantamento de dados secundários juntamente a Secretaria de Agricultura, Pecuária e Meio-Ambiente do Município de Itabaiana (SAPMA) e empresas comerciais, através de aplicação de entrevistas. Nessa etapa foram realizadas entrevistas com os intermediário-atacadistas de hortaliças e de raízes; e 5- foi realizado o mapeamento dos principais fluxos e utilizou-se de figuras, como gráficos, tabelas e registro fotográfico.

Essas etapas serviram de base para a análise dos fluxos e alcances espaciais das hortaliças e raízes produzidas, importadas e comercializadas por Itabaiana.

\section{AS REDES E OS FLUXOS COMERCIAIS DE PRODUTOS AGRÍCOLAS NA RELAÇÃO CAMPO-CIDADE}

As redes referendam aspectos intensificados com a articulação da economia rural e urbana. Por essa relação o mundo rural se organiza em torno de uma tetralogia, cuja função é produzir alimentos; a atividade econômica é a agricultura; o grupo social predominante é a família camponesa; e a paisagem, que reflete certo equilíbrio entre a natureza e a atividade humana. Enquanto a cidade se coloca com atividades, grupos sociais e paisagens bem heterogêneas e que se contrapõe ao rural (FERRÃO, 2000). Essa relação é de interdependência, pois a produção rural passa a abastecer os mercados urbanos com produtos agrícolas, como também, com mão-de-obra barata e desqualificada. Enquanto que as cidades tornam-se pólos de prestação de serviços pessoais e sociais e, por vezes, "nós" nas redes de comercialização de produtos agrícolas.

Essas redes funcionam conforme as implicações sociais, econômicas e culturais que geram como conseqüências complementaridades, inclusões e exclusões. As mesmas podem ser do tipo global ou local, refletindo instâncias de produção, distribuição, circulação e consumo. São analisadas como produto e condição social, cuja dimensão organizacional, segundo Côrrea (2005), envolve relações entre agentes sociais, origem, natureza dos fluxos, função e finalidade. Esses aspectos organizacionais são concretizados dentro de uma dimensão temporal e espacial, abarcando assim, a duração da rede e a sua abrangência escalar. Dessa forma, a mesma não deve ser tratada isoladamente, deve estar relacionada à urbanização, à divisão territorial e à diferenciação espacial.

Para Dias (1995), o termo rede aparece com a função de viabilizar duas estratégias que seriam circular e comunicar. Contudo, o mesmo pode ser referendado como “[...] projeto de integração territorial, integração de mercadorias regionais, pela quebra de barreiras físicas, obstáculos à circulação de mercadorias, de matérias-primas, mas também de capitais (DIAS, 1995, p.145). Tal conceito pressupõe a circulação de bens, pessoas e informações, e ainda, de tecnologias, de capitais e de matérias-primas, que se constituem a partir da urbanização, da divisão territorial do trabalho e da racionalidade do espaço. Esse ensejo mostra a necessidade de substituir os territórios ou regiões econômicas isoladas, por áreas articuladas em função da circulação de bens, pessoas e informações em diversas escalas. Tal processo contribui na diversificação e na heterogeneidade dos espaços. Ainda segundo Dias (1995), a conexão, ligação é uma das principais propriedades da rede.

Os nós das redes são assim lugares de conexões, lugares de poder, de referência [...] é antes de tudo pela conexidade que a rede solidariza os elementos. Mas ao mesmo tempo em que o potencial de solidarizar, do contexto, também tem de excluir [...] (DIAS, 1995, p.148).

Por esse contexto, verifica-se a importância das redes na articulação de centros urbanos para a organização espacial, no sentido de efetivar uma região economicamente forte. Isto ocorre a partir 
dos efeitos integradores dos transportes, que dentro da relação cidade-região tem reorientado a comercialização, distribuição e circulação das mercadorias.

Assim, a categoria rede é utilizada para evidenciar os fluxos, alcances e demandas, no sentido de importação e exportação, de hortaliças em Itabaiana/SE. Os fluxos possibilitam a definição de escalas de comercialização dos produtos em estudo e colaboram para demonstrar a cidade de Itabaiana como uma centralidade na sua oferta, dentro da escala local, regional e nacional.

\section{COMERCIALIZAÇÃO DE HORTALIÇAS E RAÍZES NO BRASIL E EM SERGIPE}

O grupo das hortaliças é composto por verduras e folhagens. No Brasil esse grupo apresenta índices elevados de produtividade, tendo como maior produtor o estado de São Paulo, que em 1998, respondia por 34\% da produção brasileira, sendo seguido por Minas Gerais que respondia por 18\% e Rio de Janeiro com 7\% da produção nacional. Deste modo, só esses três estados concentravam $61 \%$ da produção de hortaliças comercializadas no mercado nacional, cujos produtos de maior destaque eram: tomate, cebola, cenoura e alho (VILELA; HENZ, 2000, p.72).

Embora a produção das hortaliças seja lucrativa, elas são suscetíveis aos fatores naturais, as necessidades de água e de fertilizantes, além de cuidados contra possíveis pragas que causam prejuízos. O sucesso de um negócio que envolva a comercialização de hortaliças deve considerar que "[...] as hortaliças são culturas temporárias e, assim como as outras, necessitam de um investimento inicial. Dependendo da espécie, região e época de cultivo, os níveis de investimento podem variar de US\$1 mil a US\$5 mil por hectare" (Op. Cit., 2000, p. 73).

A produção de hortaliças é fortemente influenciada pela demanda do consumidor, cuja dinâmica comercial tem exigido novas variações em relação ao que já é conhecido, principalmente no que se refere ao tamanho, cor e sabor. Fato que tem estruturado o mercado em diversos segmentos de manejo com esses produtos, correspondendo desde a demanda por produtos in natura, ou a produtos processados, na forma de conservas, de gelados ou de supergelados, de minimamente processados, de desidratados e de liofilizado (Op. Cit., 2000, p.74).

O processamento de hortaliças proporciona algumas vantagens para a comercialização, entre as quais, a pouca necessidade de espaço para armazenamento e o menor volume de mão-de-obra nesta fase. Além disso, se apresenta como uma forma mais prática para o consumo e como estratégia para evitar de estragar quando ao natural, principalmente no que se refere ao grupo das hortaliças folhosas.

A comercialização de hortaliças tem ocorrido principalmente por intermédio do mercado atacadista, apesar das vendas acontecerem de forma direta por intermédio dos produtores, feirantes e pelas próprias redes de supermercados. Segundo Vilela e Henz (2000, p. 76), “estima-se que no Brasil entre $55 \%$ e $60 \%$ do volume de hortaliças é comercializado pela rede de CEASA(s), ainda com alta freqüência de intermediários na [...] comercialização.” Ainda para os autores, só a CEAGESP é responsável por mais de $25 \%$ da comercialização de hortifrutigranjeiros no país.

Em Sergipe, a constituição da cadeia produtiva de hortaliças e de raízes, no que se refere à produção e a comercialização, tem se localizado a partir da especialidade produtiva, isto é, alguns municípios se especializaram e ficaram conhecidos pela cultura que desenvolvem, a exemplo de Malhador, com o inhame; de Moita Bonita, com a batata-doce e de Itabaiana com hortaliças, entre outros. Apesar dessa especificidade, Sergipe conta com espaços de comercialização em todos os seus municípios, mas com apenas dois espaços de distribuição atacadista, que são: o CEASA, em Aracaju e o Mercado de Hortifrutigranjeiros, em Itabaiana.

Segundo a EMDAGRO (2007), o CEASA de Aracaju, comercializou no ano de 2007, aproximadamente 29.137,91 toneladas de hortifrutigranjeiros, sendo que em termos de hortaliças e raízes somavam 16,89\% desse total. Esses produtos têm sido importados e distribuídos tanto no mercado interno quanto no mercado externo. Segundo Santana (2005, p.136), entre os principais produtos 
importados por Sergipe desse subgrupo estão: a batata-inglesa e o tomate; enquanto entre os exportados destacam-se a batata-doce, as folhagens e o quiabo.

No município de Itabaiana esse fluxo comercial de hortaliças e raízes tem sido evidenciado em vários dias da semana, tanto no Mercado de Hortifrutigranjeiros quanto no Largo José do Prado Franco. A fim de se evidenciar os fluxos da cadeia de comercialização das hortaliças e das raízes em Itabaiana/SE e pelo número de produtos que estão envolvidos nesse subgrupo, o mesmo fora subdividido em duas vertentes conforme a importação e exportação de seus principais produtos. Sendo o termo importação aqui utilizado no sentido da aquisição de produtos fora do município de Itabaiana, assim como, o de exportação refere-se à venda de produtos para fora desse espaço.

\section{Fluxos de Importação}

O município de Itabaiana/SE apresenta um fluxo expressivo em termos de produtos que compõem o grupo de hortaliças e raízes importadas, dentre os quais se destacam: abóbora, acelga, alho, batata inglesa, beterraba, cebola, cenoura, chuchu, couve, inhame, pimentão, repolho, tomate e vagem. Esses produtos têm sido provenientes principalmente do estado da Bahia, com algumas exceções, como é o caso do tomate e do repolho, entre as hortaliças e do alho e inhame, entre as raízes que mantém fluxos na esfera regional, nacional e internacional. Tais fluxos serão analisados considerando a procedência de alguns produtos e suas respectivas movimentações internas no estado de Sergipe, a partir dos diversos pontos de recepção dos produtos comercializados no Mercado de Hortifrutigranjeiros de Itabaiana.

\section{A) Tomate}

O tomate (Lycopersicum lycopersicon) é um produto originário da América Central e do Sul, tendo sido cultivado e consumido pelos povos pré-colombianos. Pelo aspecto cultural, é exposto como um legume, quando na verdade é um fruto, uma vez que se compõe, em termos de fisiologia, de ovário e do óvulo da flor que formam o pericarpo e as sementes, após a fecundação.

A comercialização desse produto in natura é bastante regionalizada, ocorrendo em um raio de $1.000 \mathrm{~km}$ de onde foi produzido. Deste modo, a logística do tomate in natura é desfavorecida para a exportação, pois a demanda no comércio internacional é maior por esse produto processado. Neste contexto, até o Brasil se coloca como importador da pasta de tomate, principalmente da chilena (CARVALHO E PAGLIUCA, 2007, p.06).

No estado de Sergipe, o mercado de tomate é abastecido principalmente pela importação desse produto in natura dos estados de Goiás, Bahia, Minas Gerais, São Paulo, Rio de Janeiro, Espírito Santo e Pernambuco (SANTANA, 2005, p.153). Além disso, em Sergipe, o tomate é entre as verduras, um dos mais produzidos (cerca de 5.300 toneladas), mesmo com as limitações em relação à quantidade e a qualidade. Sendo o município de Itabaiana responsável pelo cultivo de $64,15 \%$ do que é produzido nesse estado.

Em termos de comercialização desse produto, tanto em nível estadual quanto no âmbito do município de Itabaiana, observa-se uma das mais complexas cadeias, em virtude do seu aspecto perecível e da distância percorrida para a importação do mesmo. Além disso, essa cadeia é realizada pelo produtor, pelo produtor-intermediário, pelo intermediário-atacadista e por varejistas (Figura 1).

O produtor de tomate normalmente comercializa sua produção na propriedade para os intermediários. Contudo, ocorre desse agricultor algumas vezes transportar sua produção para a sede municipal a fim de comercializar para atacadistas e varejistas. Ao adquirirem o produto, o intermediário local acaba comercializando sua mercadoria para outros intermediários. Os intermediário-atacadistas de Itabaiana ao comprarem o produto, promovem o seu transporte até o Mercado de Hortifrutigranjeiros, onde será comercializado para outros mediadores regionais ou para os varejistas locais. Por conseguinte, a comercialização de tomate importado em Itabaiana apresenta seu preço acrescido em função do valor da produção, do transporte, da ação dos intermediários internos e externos. 


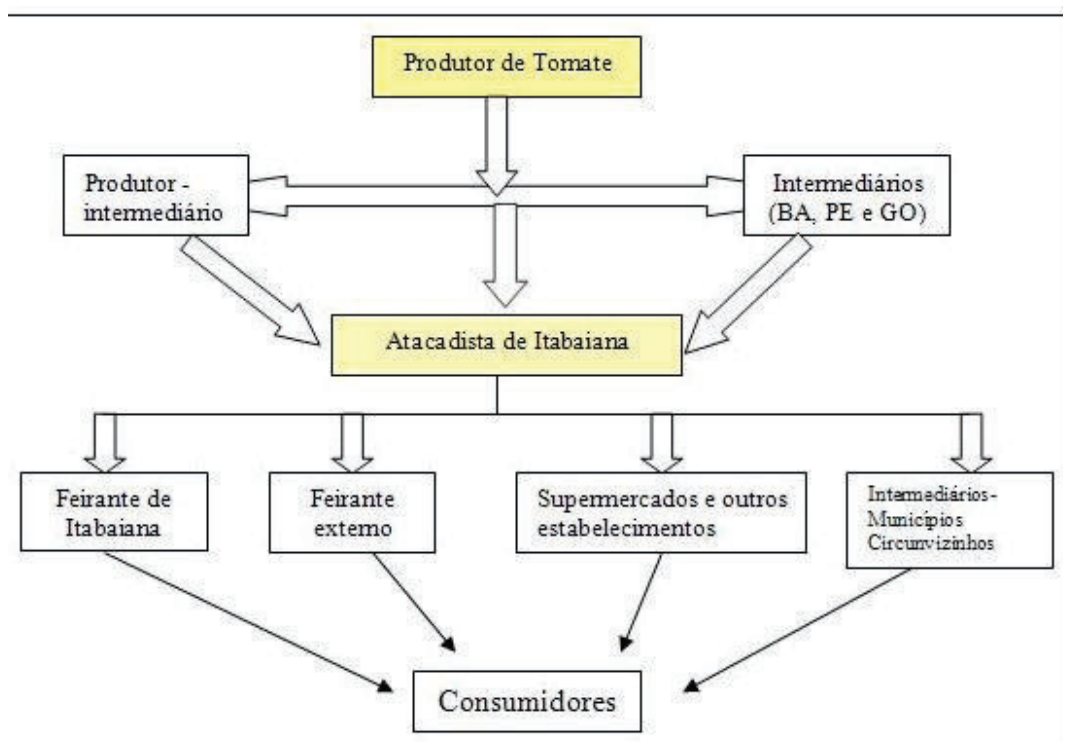

Figura 1 - Itabaiana: Cadeia de Comercialização do tomate,2009. Organização: Diana Mendonça de Carvalho, 2010.

O município de Itabaiana importa cerca de 3.500 toneladas de tomate anualmente dos estados da Bahia (Irecê, Jacobina, Jequié e Seabra), Pernambuco (Camoci de São Félix) e Goiás (Cristalina) (SAPMA) (Figura 2). Essa importação atende a demanda dos municípios sergipanos, baianos e alagoanos, sendo intensa a comercialização com os municípios contíguos à Itabaiana e com os municípios baianos de Coronel João Sá e Cícero Dantas (Figura 3). Tal comercialização é continua durante o ano e tem ocorrido principalmente nas quintas-feiras, no Mercado central da cidade, quando o produto tende a ser valorizado e direcionado a outros mercados, seja em atacado através de novos intermediários, seja em varejo, através dos feirantes (Figura 4).

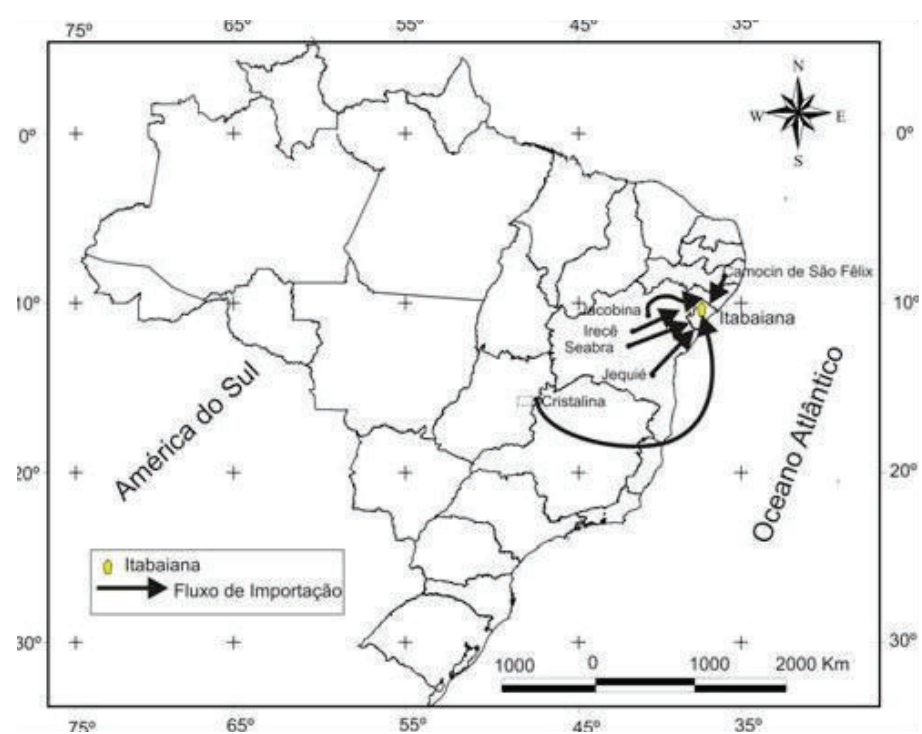

Figura 2 - Itabaiana: Fluxo de Importação de tomate, 2010. Fonte: Pesquisa de Campo e Base Cartográfica do IBGE (2005). Elaboração: Diana Mendonça de Carvalho, 2010. 


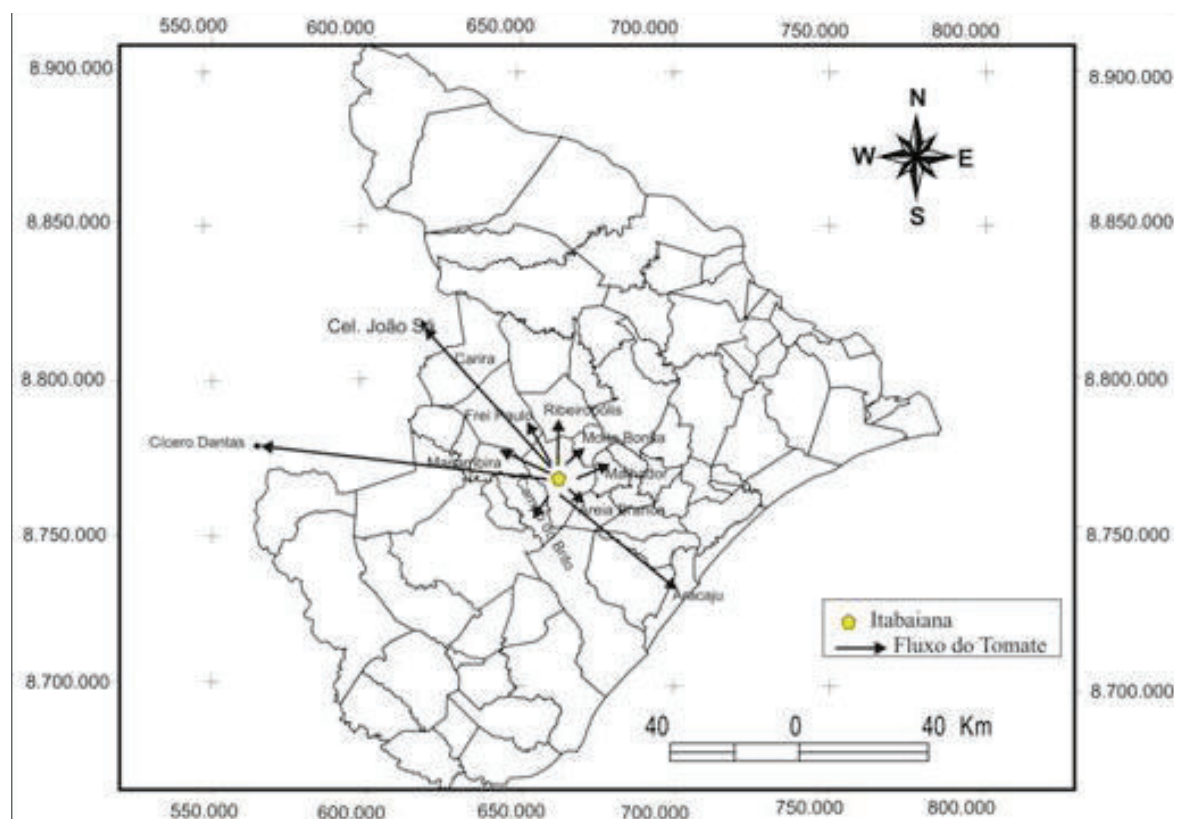

Figura 3 - Itabaiana: Fluxo de exportação de tomate.

Fonte: Pesquisa de Campo. Base Cartográfica SEPLANTEC (2004).

Elaboração: Diana Mendonça de Carvalho, 2010.

\section{B) Repolho}

O repolho é uma hortaliça da espécie Brassica oleácea, grupo Capitata, cujas folhas superiores do caule aparecem encaixadas umas nas outras, formando o que é designado como uma "cabeça". Sua origem remota há anos antes de Cristo, tendo sido cultivado na Costa Norte Mediterrânica, Ásia Menor e Costa Ocidental Européia. Posteriormente, esse produto foi disseminado e sua cultura adaptada a temperaturas elevadas, ampliando os períodos de plantio e de colheita. Assim, pela escolha criteriosa em cultivar, a época de plantio estende-se ao longo do ano, em diversas regiões produtoras (FIGUEIRA, 2000).

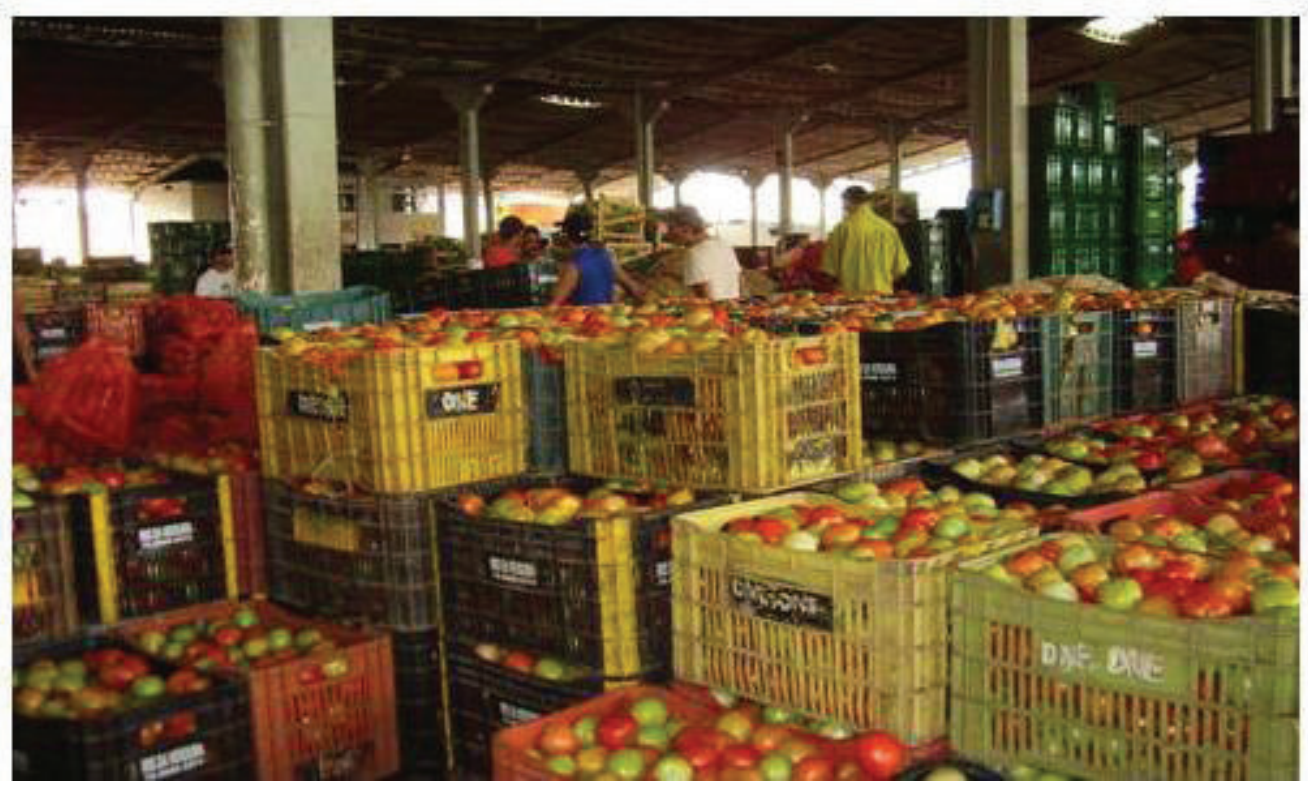

Figura 4 - Comercialização atacadista de tomate no Mercado de Hortifrutigranjeiro de Itabaiana/SE. Foto: Diana Mendonça de Carvalho, 2009. 
O Brasil produziu em 2006, 377.108 toneladas dessa hortaliça, sendo que a maior produção de repolho encontra-se no Sudeste, com 54,65\%, seguidos do Sul (28,20\%), do Centro-Oeste (10\%) e do Nordeste $(6,8 \%)$, enquanto a região Norte, produz apenas $0,35 \%$ (IBGE, 2006). Nesse contexto, o estado de Sergipe produz 1.204 toneladas de repolho, cujos municípios de maior produção são Lagarto (628 toneladas) e Itabaiana (528 toneladas) (IBGE, 2006).

Apesar da pequena produção municipal, essa hortaliça tem mercado de importação e de exportação garantidos em Itabaiana/Se, uma vez que o grande intermediário a tem adquirido junto a outros atacadistas e agricultores em mercados do Espírito Santo (Santa Maria de Jetibá e Vitória) e da Bahia (Mucugê e Paripiranga).

Por conseqüência, a cadeia produtiva do repolho se mostra alongada principalmente, quando analisada a partir do estado do Espírito Santo. Isso porque após a produção, o intermediário busca a hortaliça ensacada ou encaixotada na propriedade agrícola (povoados de Santa Maria de Jetibá) e faz seu transporte até o espaço de comercialização (Vitória). Nesse local, outros intermediários acabam adquirindo o produto e comercializando-os para grandes intermediários de Itabaiana. Além disso, pode ocorrer do próprio intermediário-atacadista de Itabaiana negociá-lo na sede do município produtor com pequenos intermediários locais. Os itabaianenses envolvidos nessa cadeia promovem o transporte até o mercado de Itabaiana, juntamente a outros produtos típicos da região ou consorciados com outros provenientes de outros estados do Sudeste brasileiro.

Esse produto também tem sido proveniente do Estado do Amazonas (Manaus), vindo juntamente com madeira. $\mathrm{O}$ intermediário da madeira que trás esse produto costuma adquiri-lo sob ordens de atacadista do setor ou por já ter um mercado direcionado e certo. Essa importação é mínima, pois os custos de transporte não favorecem a sua comercialização, segundo o intermediário. Além disso, esse produto pode não ter origem vinculada apenas a essa região, mas já ter sido importada de outras.

A comercialização realizada no mercado de Itabaiana por atacadistas locais direciona as hortaliças aos atacadistas dos estados da Bahia, Sergipe e Alagoas, assim como a feirantes e redes de supermercados.

Em termos de logística, o produto é transportado em caminhões juntamente com outros produtos, a exemplo do tomate e da batata inglesa, em sacos e caixas com pesos de 20 e $15 \mathrm{~kg}$, respectivamente.

C) Alho

O alho é uma planta herbácea anual da família das liliáceas, cujo nome científico é Allium Sativum e compõe o subgrupo das raízes, no grupo dos hortifrutigranjeiros. Além de tempero é empregado desde tempos remotos no combate a doenças, já que apresenta características medicinais para o sistema digestivo, diurético, febrífugo e é usado também como anti-séptico.

O Brasil produziu em 2006, 5.864 toneladas de alho do tipo porró, sendo a região Sudeste a maior produtora, com $73,60 \%$. No Nordeste a produção é mínima, contabilizando $7 \%$ da produção nacional, sendo a Bahia, o maior produtor, com produção de 241 toneladas (IBGE, 2006). O estado de Sergipe apresentou em 2006, uma produção de 2 toneladas, direcionada ao abastecimento do mercado local.

O município de Itabaiana não produz essa raiz (IBGE, 2006). Logo, toda a demanda por ela é atendida pela importação, advindo dos estados de Alagoas, Goiás, Rio Grande do Sul e São Paulo. Nesse último, há produção e importação dessa raiz da China e da Argentina, intermediada até a CEAGESP, onde é comercializada e adquirida pelos mediadores de Itabaiana (Figura 5). Todavia, há ainda, a aquisição dessa raiz na Argentina. 


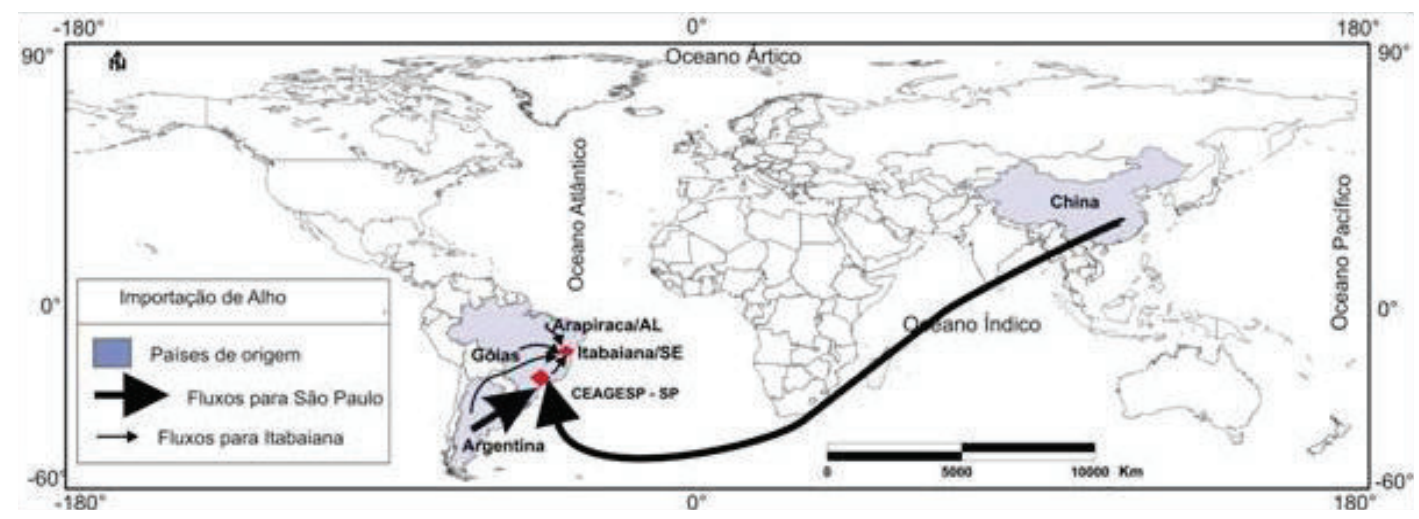

Figura 5 - Itabaiana: Fluxo de Importação de alho.

Fonte: Pesquisa de Campo. Base Cartográfica IBGE (2005).

Elaboração: Diana Mendonça de Carvalho, 2010.

Os intermediários de Itabaiana promovem o frete de mercadorias, como a batata-doce, direcionada para esse país e no retorno adquirem e traz a Itabaiana frutas e raízes, como o alho. Deste modo, a cadeia de comercialização do alho é ampla, envolvendo a importação em níveis internacional e nacional, com a participação de diversos atacadistas (Figura 6).

A aquisição do alho ocorre em sacos ou caixas favorecendo o transporte por longas distâncias dentro do país, uma vez que os advindos de outros países, normalmente chegam em containeres e nos portos são ensacados ou encaixotados e distribuídos. Entre os atacadistas do município de Itabaiana, o alho é comercializado em caixas e em sacos ou ainda, por retalho, através da exposição do produto para atender a demanda do mercado varejista, tanto de feirantes quanto de supermercados.

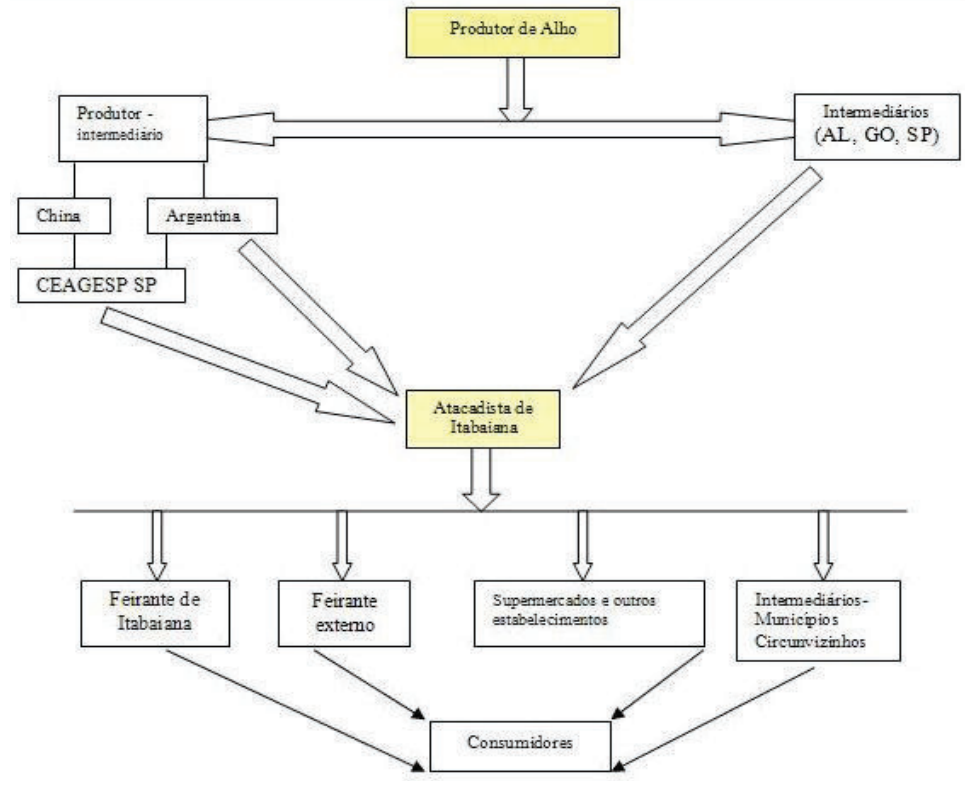

Figura 6. Itabaiana: Cadeia de Comercialização do alho. Fonte: Pesquisa de Campo.

Elaboração: Diana Mendonça de Carvalho, 2010.

A comercialização do alho em Itabaiana atende a todos os municípios circunvizinhos, ao Sertão Sergipano e também aos municípios de Aracaju, Tobias Barreto, Itabaianinha e Umbaúba, além de Coronel João Sá, Cícero Dantas, Conde, Esplanada, Crisopólis, Paripiranga e Acajutiba, todos na Bahia (Figura 7). Segundo um atacadista desse segmento, a comercialização do alho tem 
o alcance definido não só pelo fato de ser um produto de difícil aquisição no mercado, já que não é uma cultura típica de sua região, como também está associada à demanda por outros produtos, a exemplo dos condimentos e outras hortaliças. Deste modo, o varejista busca o produto juntamente com outros que comporão sua comercialização.

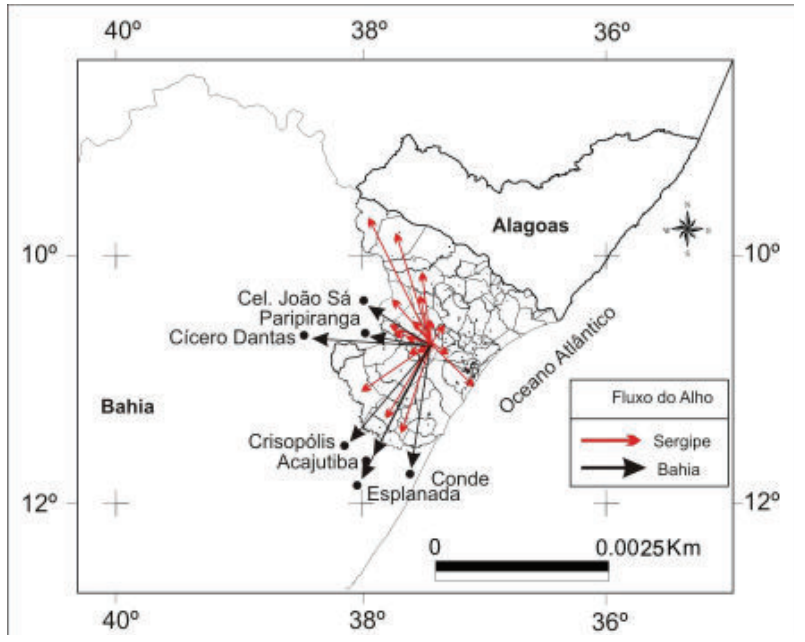

Figura 7 - Itabaiana: Fluxo de Comercialização de alho. Fonte: Pesquisa de Campo. Base Cartográfica IBGE (2005). Elaboração: Diana Mendonça de Carvalho, 2010.

D) Inhame

O inhame, planta herbácea da família das aráceas, é cultivado em regiões tropicais de todo o mundo. Os terrenos propícios para seu cultivo são brejos ou outros com alto teor de umidade. Além disso, há numerosas variedades de inhame, algumas de polpa colorida, em geral amarela ou avermelhada, mas só as de polpa branca acham-se comumente em cultivo no Brasil (ENCICLOPÉDIA BARSA, 1995).

Segundo o IBGE (2006), o Brasil produziu 99.640 toneladas dessa raiz, cujas regiões de maior produção são a Sudeste (55.571 t.) e a Nordeste (38.256 t.). No Nordeste, os estados de Pernambuco (16.574 t.), Paraíba (8.441t.) e Bahia (6.643t.) são os maiores produtores. No estado de Sergipe a produção é pequena, restringe-se a 3.464 toneladas, localizada principalmente nos municípios de Malhador (2.816 t.), Itabaiana (301 t.) e Moita Bonita (195 t.). Logo, no estado de Sergipe, 95,61\% da produção de inhame se concentra na microrregião de Itabaiana, entre os meses de dezembro e fevereiro.

Essa produção, no entanto, não atende a demanda do mercado local, pois a raiz é comercializada o ano inteiro. De acordo com a sazonalidade produtiva, o mercado de Itabaiana é abastecido por mercados de outros estados, a exemplo da Paraíba, entre fevereiro e maio; da Bahia, entre junho e outubro; e de Rondônia, entre outubro e dezembro (Figura 8). Essas raízes são transportadas em caminhões e normalmente vem consorciada com outros produtos.

A cadeia de comercialização do inhame importado de Rondônia se inicia com a obtenção desse produto junto a produtores ou pequenos intermediários urbanos. Essa aquisição é feita por um grande intermediário-atacadista de Itabaiana que realiza a condução do produto até o Mercado de Hortifrutigranjeiros, onde efetua a sua distribuição junto a médios intermediário-atacadistas da cidade. Esses médios atacadistas também compram o produto junto aos agricultores locais, no período de safra microrregional. A obtenção do inhame, nessa situação, ocorre diretamente nas propriedades dos municípios de Itabaiana e Malhador, principalmente. Posteriormente, esse mesmo atacadista faz o transporte do produto para o mercado de Itabaiana, onde são expostos em bancas 
para comercialização. Há ainda intermediários que no período de safra fazem a comercialização do produto nas carrocerias de caminhões, na lateral do mercado. Nesses casos, a comercialização ocorre tanto no varejo como no atacado.

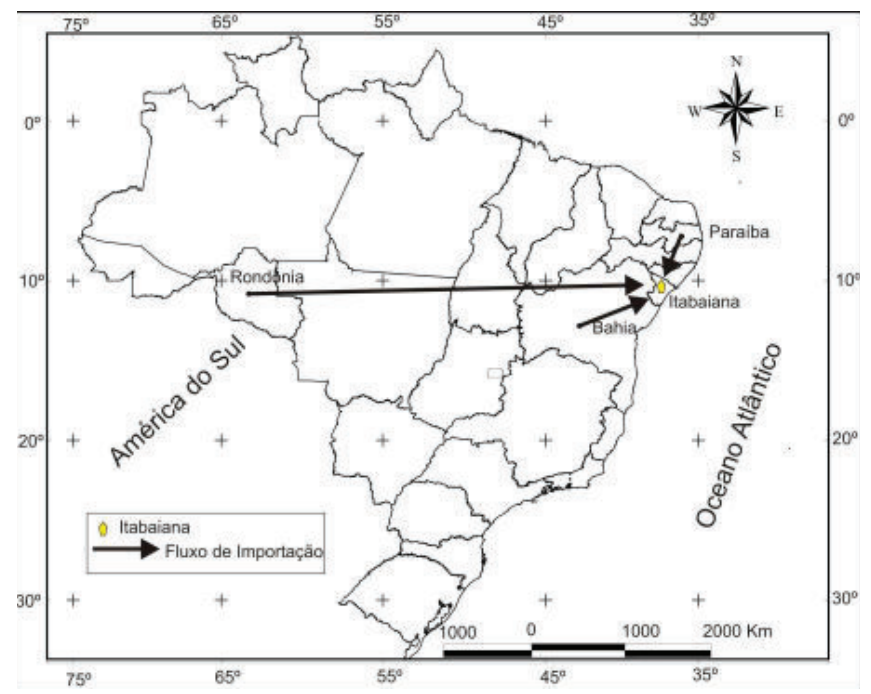

Figura 8 - Itabaiana: Fluxo de Importação de inhame. Fonte: Pesquisa de Campo. Base Cartográfica IBGE (2005).

Organização: Diana Mendonça de Carvalho, 2010.

Essa comercialização atende a demanda das redes de supermercados da própria cidade e dos municípios de Nossa Senhora da Glória, Estância, Campo do Brito, Ribeiropólis, além da demanda de fora do estado, como dos municípios de Maceió e de Delmiro Gouveia em Alagoas e de Paulo Afonso na Bahia (Figura 9).

Por esse fluxo é visível que a cadeia de comercialização do inhame segue os parâmetros das cadeias de outros produtos supracitados com a participação de produtores e intermediários em todas as fases até chegar ao consumidor final. A diferença nessa cadeia é que, ao mesmo tempo em que intermédia, o atacadista também comercializa com o consumidor final.

\section{Fluxos de Exportação}

A exportação de produtos supõe a venda para fora de uma região ou país. Nesse aspecto, tomamse como referência os produtos comercializados e encaminhados para fora de Itabaiana. Entre os produtos exportados destacam-se: batata-doce e hortaliças, especificamente o grupo das folhagens.

Tais produtos serão analisados a partir das diversas cadeias de intermediação e do alcance, identificados nas relações espaciais visualizadas durante a pesquisa de campo. Tal pesquisa contribuiu para identificar à dinâmica do comércio agrícola do município e sua inserção no mercado sergipano, regional, nacional e mesmo internacional.

\section{A) Batata-Doce}

A batata-doce, espécie Ipomoea batatas, família das convolvuláceas, é a quinta hortaliça mais cultivada no Brasil (IBGE, 2006). A mesma contabiliza uma produção de 273.126 toneladas, ficando atrás em termos de produtividade do tomate, alface, repolho e cenoura. A produção nacional de batata-doce encontra-se distribuída por regiões da seguinte forma: Nordeste (67,60\%), Sul (18,33\%), 
Sudeste $(11,15 \%)$, Centro-Oeste $(2,34)$ e Norte $(0,58 \%)$. No Nordeste o maior produtor dessa raiz é o estado de Sergipe, com uma produção de 92.851 toneladas (IBGE, 2006).

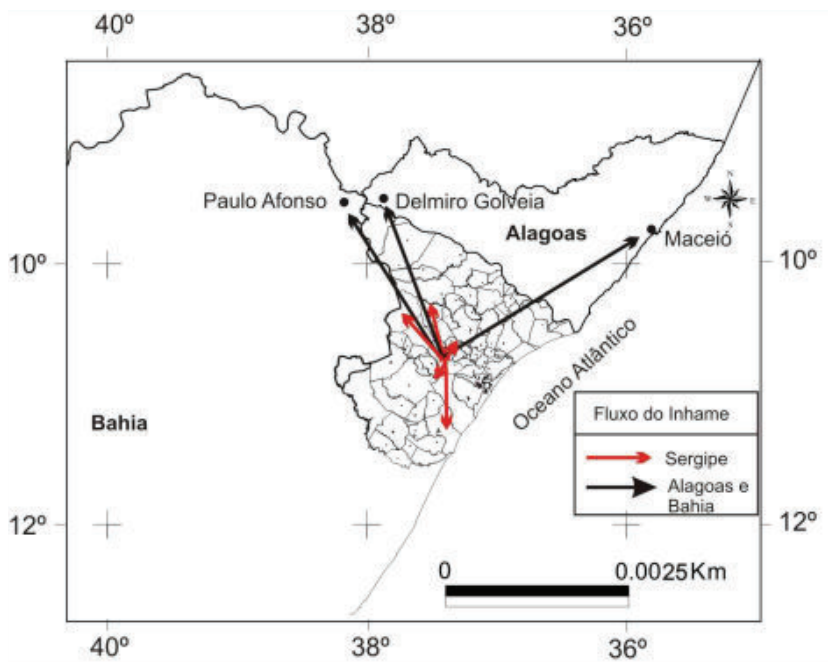

Figura 9 - Itabaiana: Fluxo de Exportação de inhame. Fonte: Pesquisa de Campo. Base Cartográfica IBGE (2005). Elaboração: Diana Mendonça de Carvalho, 2010.

Em Sergipe, o maior produtor dessa raiz é o município de Itabaiana (85,61\%), com uma produção de 79.495 toneladas (IBGE/SIDRA, 2006). A comercialização dessa raiz ocorre tanto nos espaços de produção (sítios) quanto no Mercado de Hortifrutigranjeiro de Itabaiana, ocorrendo à presença de intermediário no local de produção, no mercado de Itabaiana e no momento da exportação (Figura 10).

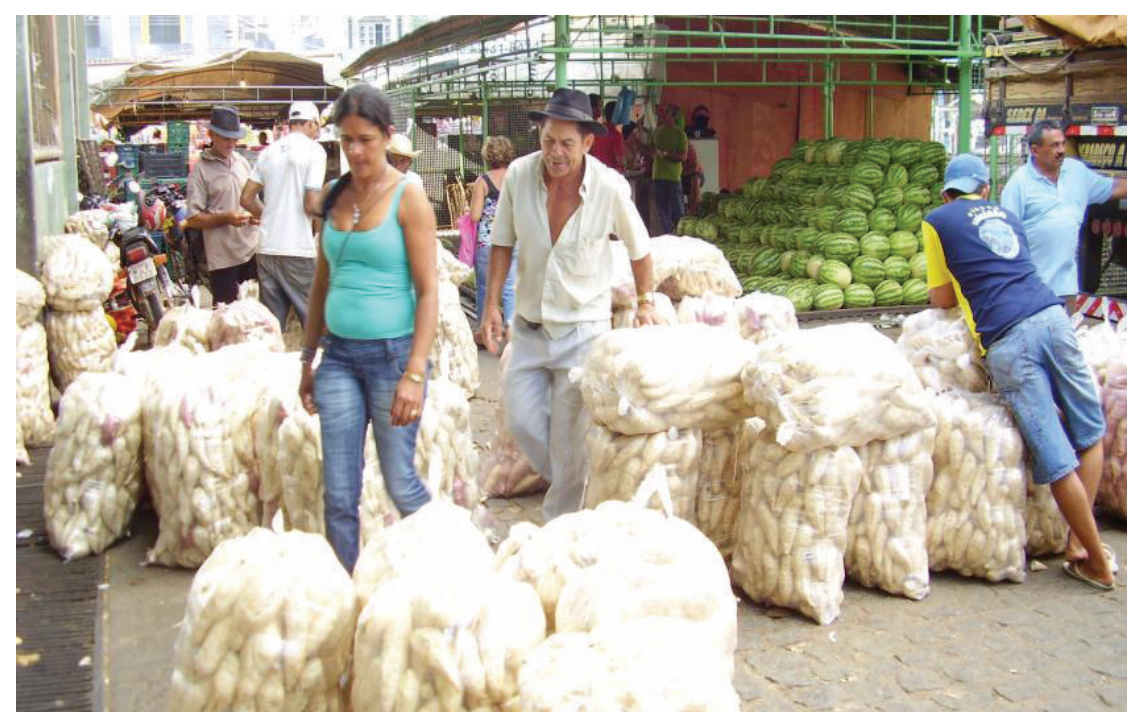

Figura 10 - Comercialização de batata-doce no Mercado de Hortifrutigranjeiros de Itabaiana. Foto: Diana Mendonça de Carvalho, 2009.

Esse produto tem o maior alcance espacial entre os negociados em Itabaiana e é constante durante todo o ano em nível interno e externo. A comercialização dessa raiz na esfera interna atende a demanda do mercado nacional, podendo ser temporária, a depender da sazonalidade, principalmente para estados nordestinos como Piauí, Maranhão, Pernambuco e Ceará, e para a região Sul; e permanente quando atende a demanda semanal de municípios de Sergipe, Bahia e Alagoas (Figura 11). 
Um grande intermediário da batata-doce de Itabaiana relatou adquirir esse produto tanto nas áreas de produção quanto no mercado de Itabaiana. Tal ator comercializa no período de safra da microrregião cerca de seis "caminhões truck" por semana. Esse processo ocorre mediante demanda do produto por intermediários sulistas e argentinos, principalmente. Estes intermediários fecham o negócio com o atacadista de Itabaiana através de uma visita, normalmente a cada semestre, ou através do pagamento antecipado de parte da carga e a outra parte perante o recebimento de toda a mercadoria, sendo o itabaianense o responsável pela condução do produto até o endereço indicado.

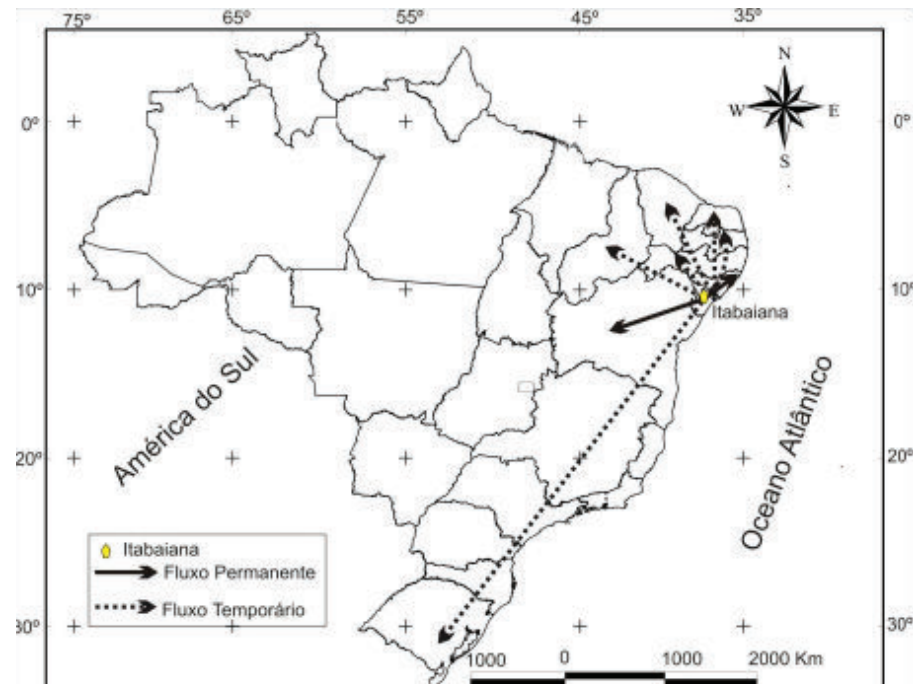

Figura 11 - Itabaiana: Fluxo Interno da Batata-doce.

Fonte: Pesquisa de Campo. Base Cartográfica IBGE (2005).

Elaboração: Diana Mendonça de Carvalho, 2010.

Essa comercialização conta com a participação do próprio produtor negociando seu produto para os intermediários locais em sua propriedade; do produtor-intermediário que comercializa os produtos no mercado de Itabaiana e do intermediário-atacadista que promove a comercialização com outros intermediários em outras partes do país (Figura 12). Esse processo de intermediação acaba estabelecendo relações de dependência entre os envolvidos na comercialização da batata-doce.

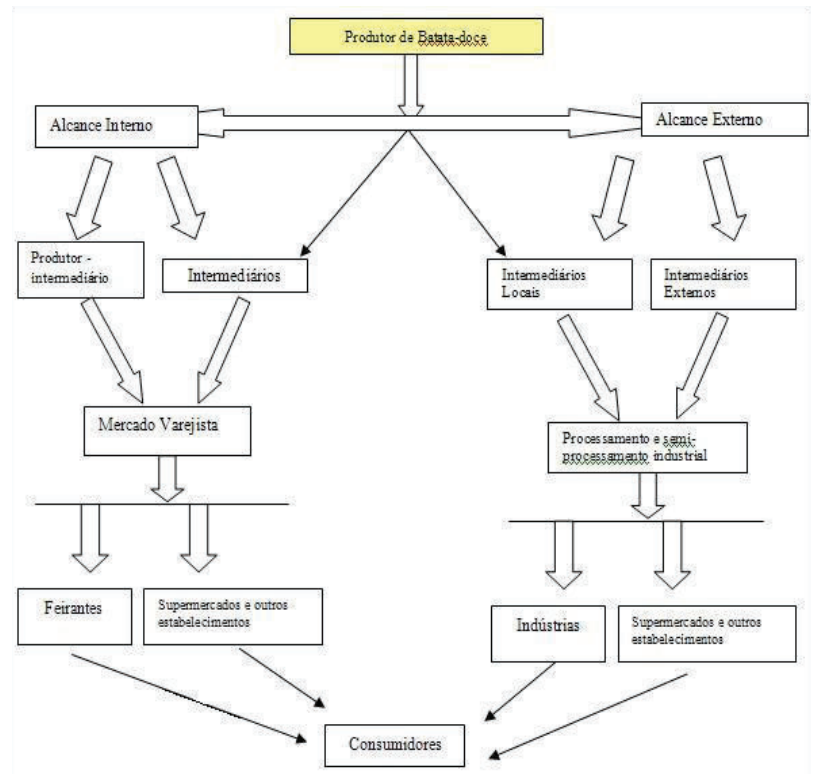

Figura 12 -Itabaiana: Fluxo de Comercialização da batata-doce. Elaboração: Diana Mendonça de Carvalho, 2010. 
A comercialização externa atende mercados internacionais, como Argentina, Paraguai e França e conta com a ação do intermediário e do atacadista externo, que vem negociar e tratar da logística do produto (Figura 13). Todavia, a exportação da batata-doce para a Argentina deve ser considerada associada à revenda promovida para o Rio Grande do Sul, visando o abastecimento da indústria de alimentos desse estado sulista. Desta forma, a cadeia de comercialização e os fluxos proporcionados por esse produto têm alcance espacial no âmbito local, regional, nacional e internacional (SANATANS, 2005).

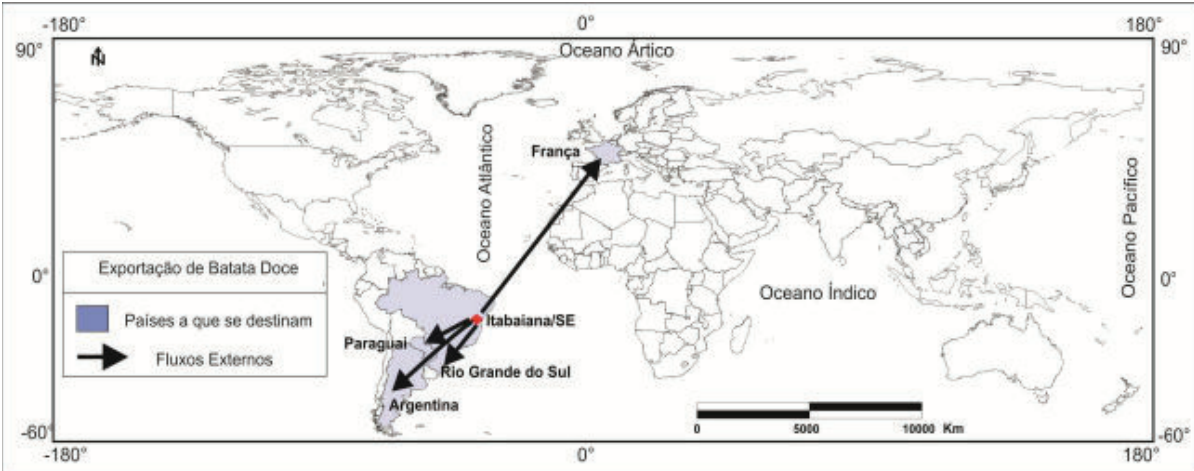

Figura 13. Itabaiana: Fluxo de Externo da Batata-doce.

Fonte: Pesquisa de Campo. Base Cartográfica IBGE (2005).

Elaboração: Diana Mendonça de Carvalho, 2010.

\section{B) Folhagens}

As folhagens compõem o grupo das hortaliças, constituídas pela alface, coentro, cebolinha, salsa, hortelã, rúcula, chicória, escarola, almeirão, rabanete e espinafre. Os quatro primeiros produtos são tradicionais em Itabaiana, enquanto os sete últimos têm sua cultura iniciada há pouco tempo, em virtude da demanda principalmente das redes de supermercados.

A produção de folhagens no Brasil, segundo dados do Censo Agropecuário, IBGE/SIDRA (2006), foi de 895.993 toneladas (Tabela 01). Fato que comprova uma produção tradicional no segmento, sendo voltados para o abastecimento direto e indireto da população brasileira. No mesmo período, foram produzidos em Sergipe 6.326 toneladas, das quais 34,47\% em Itabaiana (Tabela 1).

A produção de folhagens em Itabaiana tem como base tradicional a produção de alface, hortelã e coentro que representam respectivamente $65,51 \%, 60 \%$ e $37,80 \%$ da produção sergipana. Todavia, nos últimos anos, a produção de folhagens atípicas em termos culturais para o Nordeste tem sido cultivada em Itabaiana, como rúcula, chicória e espinafre, que são representadas na produção sergipana por $88,88 \%, 100 \%$ e $50 \%$. Tais culturas são incentivadas principalmente por empresas rurais. Uma dessas produz semanalmente 1.900 unidades de rúcula, 200 de chicória, 160 de escarola, 105 de almeirão, 180 de rabanete e 350 de espinafre.

O consumo e a comercialização desses produtos são elevados no mercado sergipano e nos mercados de estados vizinhos, como em Alagoas e na Bahia. Decorrente da fragilidade, o alcance deles é restrito a esses mercados e sua comercialização é diária entre produtores, intermediários e consumidor final. Deste modo, a produção e comercialização das folhagens atende toda a microrregião de Itabaiana, alguns municípios do Sertão Sergipano, além da capital e também municípios baianos (Coronel João Sá, Paripiranga, Juazeiro, Geremoabo, Ribeira do Pombal, etc.) e alagoanos (Arapiraca, Delmiro Gouveia, entre outros.).

A comercialização para mercados mais distantes tem sido realizada por pequenos e médios intermediários que vendem a produção para outros comerciantes de estados vizinhos e por pequenas empresas rurais do município em atendimento às redes de supermercados. Essas empresas já 
contam com técnicas e formas de manejo do produto pós-colheita, a fim de conservá-los melhor e diminuir os riscos de perdas, além de técnicas de refrigeração, da adoção de caixas de papelão e transporte refrigerado para possibilitar o aumento da vida útil dos produtos.

Tabela 1 - Brasil, Sergipe, Itabaiana: Produção de Folhagens (2006)

\begin{tabular}{l|r|r|r}
\hline \multicolumn{1}{c|}{ PRODUTOS } & \multicolumn{1}{c}{ Brasil (ton.) } & Sergipe (ton.) & Itabaiana (ton.) \\
\hline Alface & 525.602 & 841 & 551 \\
\hline Coentro & 108443 & 3719 & 1406 \\
\hline Cebolinha & 99952 & 1421 & 183 \\
\hline Salsa & 29153 & 314 & 20 \\
\hline Hortelã & 4095 & 5 & 3 \\
\hline Rúcula & 25887 & 9 & 3 \\
\hline Chicória & 25793 & 3 & 3 \\
\hline Almeirão & 32335 & 0 & 61 \\
\hline Espinafre & 34244 & 12 & 1 \\
\hline Rabanete & 10489 & 2 & 2.181 \\
\hline Total & 895.993 & 6.326 & \\
\hline
\end{tabular}

(1) O IBGE não registra a produção de escarola no Município de Itabaiana, mas pelo trabalho de campo, observa-se, pelo menos entre as empresas agrícolas, verifica-se uma pequena produção.

Fonte: IBGE (2006). Organização: Diana Mendonça de

A comercialização das folhagens já não se mostra como entrave na cadeia de produção dos mesmos, pois o mercado desse segmento tem adotado meios técnicos e científicos para aumentar a produção e atender as demandas internas e externas. Todavia, ainda permanece com a problemática da década de 1990, conforme COSTA (1992, p.157)

[...] as hortaliças são os produtos que mais enfrentam problemas no estágio do escoamento da produção, devido às características desses cultivos como, ciclo produtivo curto e a existência de um mercado certo para sua comercialização, conseqüentemente o maior problema enfrentado se prende à armazenagem dos mesmos.

\section{CONSIDERAÇÕES FINAIS}

O município de Itabaiana é o maior centro atacadista de distribuição de hortifrutigranjeiro no Estado de Sergipe. Na rede urbana de Sergipe, esse município exerce a função de nó de comercialização agrícola. Essa comercialização ocorre durante toda a semana, mas se apresenta mais intensa as terças e quintas-feiras, quando as práticas se expandem por aproximadamente $10 \mathrm{~km}^{2}$ do centro econômico da cidade, entre os largos José do Prado Franco, Largo Santo Antônio e ruas adjacentes ao Mercado de hortifrutigranjeiros, em função da atuação dos intermediários-atacadistas.

Além disso, Itabaiana tem se destacado em termos de produção e comercialização, principalmente no que se refere a folhagens e batata-doce. O primeiro, com produção de alface, cebolinha e coentro, entre outros, que tem sua comercialização direcionada aos mercados varejistas e atacadistas do estado de Sergipe e de alguns municípios do sertão baiano (Coronel João Já, Paripiranga, Juazeiro, Geremoabo, Ribeira do Pombal, etc.) e alagoanos (Arapiraca, Delmiro Gouvêa, etc.). O segundo apresenta alcances nacionais e internacionais, sendo direcionada para os mercados do Sul do país e para Argentina e França. 
Os fluxos ocasionados por esses produtos agrícolas estimulam para o enlace da relação campocidade nacional, regional e principalmente local, ao mesmo tempo em que cooperaram para alavancar rendas que passaram a compor a economia urbana e municipal.

Apesar de ser marcante a tradição do setor de produção agrícola em Itabaiana, esse já não é economicamente significativo para o município que agora tem nos segmentos de comércio e de serviço seus maiores valores agregado. Contudo, esses segmentos também são complementados com a atividade agrícola, uma vez que Itabaiana se especializa como área de comercialização desses produtos. Tal fato é favorecido pela sua localização, no centro geográfico do estado, que possibilita maior interligação do município com todas as regiões do estado e estados circunvizinhos; e pelo crescimento sócio-cultural verificado em termos populacionais urbanos.

Essas condições definem a existência de cadeias produtivas entre as hortaliças e raízes, tanto entre aquelas produzidas em Itabaiana, quanto entre as importadas e comercializadas nessa cidade. Essas cadeias podem ser compreendidas por:

1. Fornecedores de insumos, caracterizados em Itabaiana por manterem pequenos estabelecimentos localizados no centro comercial da cidade e que comercializam sementes, fertilizantes, defensivos, herbicidas, entre outros;

2. Agricultor, que é trabalhador familiar e ator social responsável pelo repasse da sua produção para outros atores integrantes dessa cadeia;

3. Intermediários, enquanto responsáveis pela aquisição, distribuição e comercialização dos produtos são visualizados nos atacadistas que atuam na negociação de hortaliças e raízes no Mercado de Hortifrutigranjeiros. Eles são considerados um entrave na comercialização pelo número de articulações que definem na comercialização de um único produto, em função da conseqüente elevação dos preços desses gêneros;

4. Varejistas que apresentam ação local, atuantes na comercialização direta com o consumidor final, subdivididos entre os feirantes e os supermercados; e

5. Consumidor final, que é o último ator no canal da comercialização.

A constituição dessa cadeia e sua manutenção têm contribuído para que a cidade de Itabaiana se mantenha como o maior centro de comercialização e de fluidez do estado, sendo responsável em grande parte, pela logística e transporte das mercadorias agrícolas, tanto em relação aos produzidos no município como em relação aos importados e exportados. Há produtos intermediados por atacadistas de Itabaiana que não chegam nem a entrar na cidade, pois já têm mercados certos, acordados pelo atacadista e pelo intermediário regional que fará a distribuição dos produtos adquiridos junto ao atacadista de Itabaiana, para feirantes e supermercados de outros municípios sergipanos, baianos e alagoanos.

Deste modo, o alcance espacial dos produtos comercializados em Itabaiana, por si só já explica a dinâmica do comércio de gêneros agrícolas no município. Por esses ainda, é notório que Itabaiana é um "espaço de circulação, de distribuição e de consumo", onde o fluxo de comercialização pode ser material com a exposição da mercadoria e imaterial com o repasse da mercadoria sem apresentação prévia do produto através da comercialização a termo.

\section{REREFÊNCIAS BIBLIOGRÁFICA}

Associação da Batata Brasileira (ABBA). Produção Brasileira de Batata Inglesa. Agosto, 2007. Disponível em $<$ http://www.abbabatatabrasileira.com.br/images/pdf/batatabrasil_app.pdf $>$. Acesso em 23 de novembro de 2009. 
Associação da Batata Brasileira (ABBA). Produções e Áreas Mundiais de Batata Inglesa. (2004). Disponível em $<$ http://www.abbabatatabrasileira.com.br/images/pdf/batatamundo_app.pdf $>$. Acesso em 23 de novembro de 2009.

CARVALHO, J. L. De e PAGLIUCA, L. G. Um mercado que não pára de crescer globalmente. CEPEA, USP, junho de 2007, Disponível em <http://www.cepea.esalq.usp.br/hfbrasil/edicoes/58/mat_capa.pdf $>$. Acesso em 17 de novembro de 2007.

CÔRREA, R. L. Trajetórias geográficas. $3^{\circ}$ ed. Rio de Janeiro: Bertrand Brasil, 2005.

COSTA, J. E. da. O Campesinato em Itabaiana (Se): Uma abordagem Chayanoviana. Dissertação de Mestrado. São Cristóvão: NPGEO/UFS, Agosto, 1992.

DIAS, L. Redes: Emergência e Organização. In: CASTRO, I. E. de (Org.). Geografia: Conceitos e Temas. Rio de Janeiro: Bertrand Brasil, 1995.

EMDAGRO. Boletim de Comercialização Agrícola, ano 2007. Secretaria de Estado da Agricultura e do Desenvolvimento rural e agrário. Aracaju: Governo de Sergipe, 2007. Disponível em < http://www.emdagro. se.gov.br/modules/wfdownloads/singlefile.php?cid=1\&lid=223>. Acesso em 30 de maio de 2009.

CEncyclopaedia Britannica do Brasil (BARSA). Publicações Ltda. Cd-Room, 1995.

FERRÃO, J. Relações entre mundo rural e mundo urbano: evolução histórica, situação actual e pistas para o futuro. Santiago: EURE, Vol. 26, $n^{\circ}$ 78, Set. 2000, p. 123-130. INSS. 0250-7161. Disponível em World wide web $<$ http://scielo.cl/scielo.php?script=sci_arttext\&pid=S0250-71612000007800006\&Ing=es\&nrm= iso $>$. ISSN 0250-7161. Acesso em 03 de junho de 2008.

FILGUEIRA, F.A.R. Novo manual de olericultura: agrotecnologia moderna na produção e comercialização de hortaliças. Viçosa: UFV, 2000.

IBGE. Censo Agropecuário. Rio de Janeiro: 2006. Disponível em < ftp://ftp.ibge.gov.br/Censos/Censo_Agropecuario_2006/Censo_Agropecuario_2006.zip>. Acesso em 18 de janeiro de 2009.

SANTANA, J. W. C. de. Comercialização Agrícola no Estado de Sergipe. Dissertação de Mestrado em Geografia. São Cristóvão: Núcleo de Pós-Graduação em Geografia, NPGEO/UFS, 2005.

Secretaria de Estado do Planejamento e da Ciência e Tecnologia - SEPLANTEC. Atlas Digital.Aracaju, 2004. VILELA, S. L. de. Globalização e Emergência de Múltiplas Ruralidades: Reprodução Social de Agricultores Via Produtos para Nichos de Mercado. Tese de Doutorado em Ciências Sociais, Instituto de Filosofia e Ciências Humanas da Universidade Estadual de Campinas. São Paulo: Setembro/1999. Disponível em < http://gipaf.cnptia.embrapa.br/publicacoes/artigos-e-trabalhos/tese-completa1.pdf/view>. Acesso em 25 de novembro de 2008 .

Trabalho enviado em janeiro de 2011 Trabalho aceito em abril de 2011 